Doi: $\underline{\text { dx.doi.org/10.17921/2525-5320.2016.303-309 }}$

\title{
FORMAÇÃO TÉCNICA PROFISSIONAL EM SAÚDE E AS FORTALEZAS DA PEDAGOGIA DE SCHOENSTATT PARA ATUAÇÃO NA PROMOÇÃO DA SAÚDE
}

\author{
Tatiane Angélica Phelipini Borges* - Mater Ter Admirabilis \\ Natacha Bolorino* - Mater Ter Admirabilis \\ Flávia Luísa Dias* - Mater Ter Admirabilis
}

Palavras-chave: Pedagogia de Schoenstatt. Educação Profissional. Promoção da Saúde.

\section{INTRODUÇÃO}

O delineamento das dimensões que a educação tem ocupado nas últimas décadas deve-se ao fato de ser considerada como instrumento e mobilização sociais, e principalmente, como agente transformador de pessoas e de uma sociedade.

A educação é reconhecidamente uma atividade humana fundamental, pois envolvem pessoas com diferentes conhecimentos na proposição de serem compartilhados para concretizar a ação de educar e autoeducar-se, de maneira que sejam respeitados os preceitos éticos, sociais, morais, cognitivos, políticos e legais do ser humano em seu contexto sociocultural e institucional (GATTI, 2013).

Para tanto, é necessário que se atente para os novos paradigmas contemporâneos da educação, da sociedade e do mundo do trabalho. Não somente a instituição de ensino precisa estar preparada para estes desafios, mas também os docentes. A escolha da melhor metodologia de ensino a ser empregada deve estar de acordo com o que se espera dos futuros profissionais, de modo que seja um modelo de inclusão social e acolha sem desqualificar (TEDESCO, 2010).

O modelo ideal é aquele que sabe lidar com a heterogeneidade, respeita as adversidades e acolhe todos os envolvidos para que haja a construção do saber diante da aprendizagem significativa. Deve-se despertar nos educandos o

\footnotetext{
*E-mail: tatiphelipini@hotmail.com

*E-mail: natachabolorino@hotmail.com

*E-mail: flaviald.nutricao@gmail.com
} 
entendimento de que suas ações são consequências de uma apreciação interior, e de que tão importante quanto a formação científica e ética está a formação cristã, nos quais favorecerão o futuro profissional e pessoal com autonomia e liberdade em prol do bem para si e para sociedade (CENTRO DE EDUCAÇÃO PROFISSIONAL MATER TER ADMIRABILIS, 2015).

Neste contexto, o sistema metodológico de ensino de Schoenstatt proposta pelo Padre José Kentenich fundador da Obra Internacional de Schoenstatt na década de 1910, oportuniza reconhecer que a atividade humana de educar em espaços pedagógicos requer planejamento de ações e comportamentos projetados com intuito da alcançar metas comuns entre os atores envolvidos. Ao mesmo tempo, possibilita que a instituição de ensino deve ser promotora e norteadora da construção do saber, sem, contudo, impor o conhecimento ao educando, e sim, objetivar a edificação dos saberes de maneira a atender seus anseios (COLÉGIO MÃE DE DEUS, 2015).

Segundo Padre Kentenich (1997), em seu modelo de ensino, a educação deve ser fortemente vinculada a teoria científica e a vida. As novas descobertas advindas de pesquisas devem ser aplicadas na prática. A instituição de ensino deve ser vista como uma instituição mediadora da sociedade, cujo elemento essencial é a pessoa humana aliada a seus avanços tecnológicos e descobertas, devendo ser cerceada pela promoção, manutenção da vida com dignidade, liberdade e autonomia.

A entidade promotora de ensino deve atender não somente aos sonhos individuais de cada educando, mas também promover condições para que esses novos profissionais, especialmente da área da saúde, consigam atuar em prol da comunidade, de modo que se possam propagar conhecimentos à população para que ela se sinta empoderada e seja o principal responsável por sua saúde-doençacuidado (CENTRO DE EDUCAÇÃO PROFISSIONAL MATER TER ADMIRABILIS, 2015).

A educação voltada para formação de futuros profissionais da área da saúde deve estar comprometida também com novo poder de cidadania presente na sociedade. Ela deve ser compreendida como uma estratégia a fim de contemplar o conhecimento científico dos educandos com a excelência técnica, aliado à relevância social advindo do setor da saúde. O compromisso com os ideais da sociedade não podem ser colocados em segundo plano, mas sim pensados para 
melhorar as condições e qualidade de vida da população (COSTA; MIRANDA, 2008).

Nessa perspectiva, o Centro de Educação Profissional Mater Ter Admirabilis (CEPMTA) que é uma instituição de ensino técnico profissional voltado para área da saúde, pertencente à Irmandade da Santa Casa de Londrina (ISCAL), entidade hospitalar filantrópica, oferece cursos técnicos de Enfermagem, Análises Clínicas, Podologia e Radiologia, cuja preocupação é de empregar uma metodologia de ensino-aprendizagem que proporcione o conhecimento técnico científico aos educandos sem se desvincular da educação cristã que oferece subsídios para prepará-los para vida profissional e pessoal com a preocupação social voltada para saúde-cuidado da população.

O CEPMTA tem sua origem e sustentação pedagógica de ensino alicerçada na Obra Internacional de Schoenstatt proposta pelo Padre José Kentenich cuja missão é voltada para formação técnica de profissionais da área da saúde, promovendo o desenvolvimento da pessoa humana de maneira integral, ou seja, intelectual, biopsicossocial, religioso, afetivo e ético. Permeados por valores humanos e cristãos que conduzem o processo pedagógico cerceado por metas autênticas na edificação de personalidades protagonistas e atuantes na sociedade.

Diante do exposto, o objetivo desse trabalho foi o de relatar a experiência de um curso técnico da área da saúde que emprega a metodologia pedagógica de Schoenstatt proposto pelo Padre Kentenich para a formação da pessoa humana em todo seu contexto biopsicossocial e cristão para sua atuação na promoção da saúde da comunidade durante o curso.

\section{DESENVOLVIMENTO}

Dessa forma, teve-se a pretensão de contribuir com a disseminação de um método de educação que podem ser empregados também em cursos de nível técnico na área da saúde, por oferecer ferramentas para enfrentar os desafios do novo contexto educacional, e que podem auxiliar no planejamento de ações voltadas para o novo perfil epidemiológico da população. Na atual conjuntura de ensinoaprendizagem, no qual compreende a formação profissional, pessoal e desenvolvimento integral de seus educandos estendendo-se para população, não encontrou-se relatos de que o método pedagógico de Schoenstatt tenha sido implementado. 
Assim, é fundamental que as instituições de formação de profissionais da área da saúde, sejam elas superiores ou técnicas estejam preparadas para atender as demandas sofridas pelas macrotendências do cuidado, cuja realidade vai além do contexto do modelo de assistência à saúde permeada pela hegemonia médica e hospitalocêntrica. A nova direção para a área da saúde indica que a prevenção e promoção saúde são essenciais para que possam contemplar as novas exigências de saúde-doença-cuidado da população.

Nessa perspectiva, todos os profissionais da área da saúde devem estar preparados para atuar de acordo com novo perfil epidemiológico dos brasileiros e sua crescente demanda de saúde advinda com a nova realidade do aumento da expectativa de vida da população, e consequentemente, às novas exigências.

A promoção da saúde é uma estratégia que permite à população adquirir maior controle sobre seu processo de saúde-doença-cuidado, além de oportunizar visibilidade aos fatores de risco e aos agravos à saúde, por meio de conhecimentos, atitudes e comportamentos favoráveis, permitindo-lhes o empoderamento e tomada de decisões, com diferentes enfoques teórico-práticos, de maneira coletiva e ambiental, reduzindo assim, as situações de vulnerabilidade e condições adversas à saúde (BUSS, 2000; SANTOS et al., 2012).

Assim, a promoção da saúde pode ser considerada como um seguimento transformador, capaz de melhorar as condições de vida e saúde da população, e que somente pode ser viabilizada quando existem profissionais e estudantes da área da saúde preparados e com competência técnico-científica para atuarem junto à comunidade diante de suas particularidades. O aprendizado de todos os agentes envolvidos requer embasamentos político, social e cristão para compreensão da importância e essencialidade dos determinantes e condicionantes sociais e de saúde (SALAZAR, 2012; KENTENICH, 1997)

Neste contexto, o CEPMTA recebe convites da sociedade civil e política para atuar na comunidade por meio de Eventos Sociais, Culturais e diversos outros temas promovendo a Educação para Saúde da população. Assim, os educandos dos cursos da área da saúde de técnico em enfermagem, de análises clínicas, de radiologia e podologia se inserem na sociedade desenvolvendo ações de prevenção e promoção da saúde junto à comunidade.

Esses eventos têm por finalidade a inserção dos educandos acompanhados pelos docentes em cenários de atuação, proporcionando que coloquem em prática a 
teoria vista em sala de aula, funcionando também como um campo de estágio. Com ações de educação em saúde possibilitam a troca de informações com a comunidade relacionadas a doenças, tratamentos, prevenção e cuidados. Bem como, exercitam seu lado profissional realizando a promoção da saúde.

Os estudantes de técnicos de enfermagem participam anualmente do evento internacional Hepatite Zero cujo objetivo e informar e conscientizar a população de que as hepatites virais dos tipos B e C matam duas vezes mais que a AIDS, mas se os indivíduos forem conscientizados quanto à prevenção e tratamento, elas poderão ser erradicadas do planeta dentro de 15 a 20 anos (HEPATITE ZERO, 2016).

Além disso, participam de eventos comemorativos do município com intuito de promover e educar em saúde quanto a doenças que podem ter um desencadeamento silencioso, tornando-se crônicas, como a Hipertensão Arterial Sistêmica e Diabetes Mellitus tipo II, com a aferição de pressão arterial e teste glicêmico capilar.

Os educandos do curso de radiologia promovem e participam de campanhas anuais de prevenção e conscientização de acidente de trânsito, algo de suma importância para população, visto que, segundo o relatório do Ministério da Saúde de 2011 a taxa de mortalidade por causas externas no Brasil ocupou o segundo lugar em números de mortes nas regiões norte, nordeste e centro-oeste, e terceiro lugar nas regiões sul, sudeste, sendo considerado importante problema de saúde pública (BRASIL, 2011).

Ademais, participam também de eventos que promovem a prevenção do câncer de mama, que é o tipo de câncer mais comum entre as mulheres no mundo e no Brasil. Dessa forma, é de suma importância as campanhas de prevenção, visto que, quando detectado na fase inicial aumentam as chances de tratamento e cura (INCA, 2015).

Por fim, os educandos de podologia além de fazerem o atendimento aos portadores de Diabetes Mellitus no CEPMTA, cuja complicação desencadeia úlceras no pé decorrentes da doença, também fazem a Educação em Saúde, tanto dos pacientes atendidos quanto da população em geral durante a participação de eventos que ocorrem na cidade de Londrina.

Para tanto, o CEPMTA cumpre seu papel, cuja intencionalidade traz arraigado junto a Pedagogia de Schoenstatt a convicção da educação como ação coletiva, dado seu processo democrático, coletivo e participativo. O educar com liberdade, 
amor e autonomia para que possam ter enraizado em si a responsabilidade pelo essencial papel que desempenham para saúde da população. É no centro formador, ou seja, na escola em que devem ser passados valores e responsabilidades para vida profissional, servindo também para vida pessoal, pois, ali deve estar a gênese do aprendizado, e não aprender com sua prática no futuro (ANWANDTER, 2004, p. $73,74)$.

\section{CONCLUSÃO}

Conclui-se que a Pedagogia de Schoenstatt proposta pelo Padre Kentenich desde 1910 é uma metodologia completa e contemporânea, pois visa não somente a formação educacional do estudante, mas foca também em seu desenvolvimento biopsicossocial e cristão, preparando-o para vida profissional e pessoal para atuação em ações sociais com autonomia e amor.

Aliado a isso, a educação em saúde é um importante instrumento de promoção e de estímulo para o autocuidado da população. Espera-se que este relato de experiência possa contribuir para reflexão de todos os envolvimentos na formação profissional de todos os níveis educacionais para subsidiar ações integrais à saúde de forma resolutiva, de qualidade e humanizada contextualizando com uma metodologia de ensino-aprendizagem diferenciada.

\section{REFERÊNCIAS}

ANWANDTER, $H$. Testimonios el $P$. José Kentenich y el nuevo orden social. Conociendo Schoenstatt, n.8, 2004.

BUSS, P.M.. Promoção da saúde e qualidade de vida. Ciênc. Saúde Colet., v.5, n.1, 2000.

BRASIL. Ministério da Saúde. Plano Nacional de Saúde 2012 - 2015: Brasília: MS, 2011.

CENTRO DE EDUCAÇÃO PROFISSIONAL MATER TER ADMIRABILIS. Projeto Político Pedagógico. Irmandade Santa Casa de Londrina - Educação Profissional Técnica na Área da Saúde. Londrina - PR, 2015.

COLÉGIO MÃE DE DEUS. Projeto Político Pedagógico. Instituto Social, Educativo e Beneficente Novo Signo, Colégio Mãe De Deus - Educação Infantil, Ensino Fundamental e Médio. Londrina - PR, 2015. 
COSTA, R.K.S.; MIRANDA, F.A.N. Formação profissional no SUS: oportunidades de mudanças na perspectiva da estratégia de saúde da família. Trab. Educ. Saúde, v.6, n.3, p.503-518, 2008.

GATTI, B.A. Educação, escola e formação de professores: políticas e impasses. Educar em Revista, n.50, p.51-67, 2013.

HEPATITE ZERO. Projeto Mundial de Erradicação. 2016. Disponível em: http://www.hepatitezero.com.br/campanha.html. Acesso em: 25 Jun 2016.

INSTITUTO NACIONAL DE CANCÊR JOSÉ DE ALENCAR. Cancêr de mama: é preciso falar disso. Rio de Janeiro: INCA, 2015.

BRASIL. Ministério da Saúde. Plano Nacional de Saúde 2012-2015: Brasília: MS 2011.

KENTENICH, J. Minha filosofia de educação. Santa Maria-RS, 1997.

SALAZAR, L. Reflexiones y posiciones alredor de la evaluación de intervenciones complejas - salud pública y promoción de la salud. Santiago de Calle: Programa Editorial de La Universidad del Valle, 2011.

TEDESCO, J. Presentación. In: OLIVEIRA, D.A. et al. Políticas educativas y territorios: modelos de articulación entre niveles de gobierno. Buenos Aires: IIPE/UNESCO, 2010. p.1-4.

SANTOS, A.A.G. et al. Sentidos atribuídos por profissionais à promoção da saúde do adolescente. Ciênc. Saúde Coletiva, v.17, n.5, p.1275-1284, 2012. 